\title{
Ladies Figure Skating as an Element of Russian Soft Power in the International Arena
}

\author{
Andrey Volkov \\ Global Sudies Department, Lomonosov Moscow State University, Moscow, Russia \\ Email address: \\ springs89@mail.ru

\section{To cite this article:} \\ Andrey Volkov. Ladies Figure Skating as an Element of Russian Soft Power in the International Arena. Journal of Political Science and \\ International Relations. Vol. 4, No. 1, 2021, pp. 1-7. doi: 10.11648/j.jpsir.20210401.11
}

Received: December 24, 2020; Accepted: January 13, 2021; Published: January 22, 2021

\begin{abstract}
This article examines Russia's growing attractiveness around the world through the prism of its athletic performance. With the beginning of the new millennium, Russia's status in the sports world is attracting great international and scientific attention. Over the past three decades, in the context of the geocultural paradigm of the development of the global world, the process of shaping the humanitarian dimension in world politics has clearly emerged. Humanitarian problems are of particular importance in modern international relations. Their solution depends on the state of international relations, the level of their tension and conflict, as well as the involvement in this process not only of official representatives of states, but also of representatives of the general public, including the sports community. Sport is a global phenomenon. At its best, it has the ability to bring people together regardless of their background, upbringing, religious beliefs or economic status. In a positive manifestation, sport serves as a tool for intercultural cooperation, aimed at peacemaking, overcoming conflicts and achieving intercultural dialogue. As such, sport is widely recognized as an important source of soft power resources for any international actor. This is especially true for modern Russia, since one should not forget that sports victories are associated today with the strength of the state, its authority and image on the world stage. The key research object of this article is figure skating as a sports component of the "soft power" arsenal of modern Russia. Using the sport of women's figure skating as an example, the article explores how Russia uses soft-power tools of influence in the intersecting arena of politics, sports and foreign policy to consolidate regional and global hegemony through a combination of different strategies. These include regular successful hosting and participation in major sporting events; development of national sports content; a positive cumulative rating in international competitions compared to other contenders for international influence. The article argues that in the modern world, sport is an instrument of political influence with a powerful potential and capabilities. It identifies shortcomings in the development of the Russian potential of such a sport as figure skating, examines possible prospects and highlights the main directions for a more fruitful use of figure skating as a tool of diplomacy and "soft power".
\end{abstract}

Keywords: Sport, "Soft Power”, Figure Skating, Russia, Public Image, Sports Diplomacy, Sports Star, Promotion, National Brand

\section{Introduction}

In the era of globalization, sport is undergoing a transition from a cultural-historical to a socio-political phenomenon. A distinctive feature of sports in the modern world is its obvious institutionalization in the context of a market economy and an information society. In fact, sport is becoming a new historical form of institutionalization of socio-economic processes. The connection between sport and politics in the 21 st century is becoming more and more evident. International sportы is actively used today for ideological and political purposes, approaching to become the stage of mainstream politics. As a result of state intervention in the field of sports, it becomes one of the strategic instruments of countries in their foreign and domestic policies. Sport acts as a state machine of nonadministrative influence on public perception and collective representation.

Commenting on the usefulness of sport as a tool that contributes to the development of diplomatic relations and the world order in general, world leaders note that it "can change the world, because it has the power to inspire; it can 
unite people in a way that little else can, and it is a sport that can awaken hope where there was only despair before" [20]. This iconic definition reflects the changing reality of the international system, in which states value the soft power potential of sport as a subtle alternative for gaining political advantage on the international stage. It also supports the argument that politics permeates all elements of social existence, including sports.

Preserving the achievements of the Soviet legacy, in Russia such a sport as figure skating has become more than just a popular sport for the country - in a sense, it can be called the personification of the nation, part of Russian culture, and an element of national heritage. According to the President of the Russian Federation V. Putin, "such a bright, beautiful, elegant sport as figure skating attracts the attention of the world community, especially now, when our athletes, and especially young athletes, achieve such stunning results, millions of people always pay attention to this, and this is not a joke, it is important when people who are involved in some kind of activity that attracts the attention of millions of people do other positive work, it only becomes more effective" [17]. In this context, it is quite obvious that figure skating can play the role of much more than just a sport given the high support and approval of the world community, Russia can skillfully and effectively use its potential of this sport on the international agenda, disseminating and relaying own culture and diplomatic intentions.

However, the question naturally arises of whether Russia is sufficiently productively using the figure skating sports potential, and whether this sport will be able to take an honorable place among such soft-power and diplomatic tools as the famous "ping-pong", "hockey", or "football" diplomacy.

\section{Results and Discussion}

\section{1. "Soft Power" and Sports Capabilities}

Through the prism of international relations and political science, countries use public diplomacy and soft power to acquire a better image and achieve their international goals.

The use of the possibilities of sports diplomatics to strengthen the foreign policy influence of the state fits perfectly into the concept of "soft power" put forward by J. Nye as a reflection of "the strength of the state, manifested in all spheres of the domestic and foreign policy of the state" [14, p. 96].

According to J. Nye, strength is the ability to influence others, create results, and lead relationships. In international relations, J. Nye described hard power as military and economic opportunities since they are the main instruments that can create threats or incentives. But the author offers other forms of power in world politics to attract players and influence the agenda, not just military force or economic sanctions. It is "soft power" that relies not on military force or sanctions but on the ability to shape the preferences of others through attraction and seduction [14, p. 97].
In other words, within the framework of this concept, it is assumed "the use of humanitarian, cultural influence, the attractiveness of the economic model of the state development, the degree of development of the state in the scientific and technical sphere, the state of ecology, the environment, the demographic situation, issues of economy, energy, defense" [5].

The main "sources of trust" in "soft power" are governments, non-governmental and intergovernmental organizations, the media, and markets, while the recipients of soft power are foreign governments and the foreign public. Thus, culture, high or mass, including the culture of sports, plays an important role in the "soft-power expression" of diplomacy.

According to B. Signitzer and T. Coombs, "the goal of diplomacy is to convey a favorable image of your country, culture, branding, to promote diplomatic activity in general" [19, p. 140]. Note that, according to J. Nye, when a country's culture includes universal values, and its policy promotes values and interests that are shared by others, it increases the likelihood of achieving the desired results due to the relationship of attractiveness and magnetism that it creates [13]. From the point of view of S. Anholt, culture also enriches the national brand, inculcating it in culture and history [2, p. 29].

Projecting the above aspects into the plane of sport, it can be agreed with the opinion of J. Szondi, who establishes a link between the role of sport and culture in the context of national branding and public diplomacy, arguing that governments lobbying for cultural or sports events also pass under the auspices of PR when relations develop with key decision-makers [22, p. 335].

\subsection{From the "Soft Power" to Sports Diplomacy}

So, the sport has long been a powerful conductor of peace, a tool for establishing relationships between different regions, peoples, often remaining the only high-quality platform for communication between peoples, especially in cases when relations, for example, between different states are in deep political or economic crisis [4, p. 9]. Nevertheless, quite often throughout the history of mankind, there have been cases when sports, sports competitions in general, were a kind of weapon of pressure, influence on states and, in fact, were a tool that finds its application in the political plane. In many ways, the main reason for the constant interest of politicians in sports is "the desire to prove the sports superiority of the nation and the total competition of the nations in the world stage" [9].

In other words, individual states sometimes tried to influence the sports component using various methods mainly through administrative and financial channels. Besides, actually in all countries, sports teams participating in international competitions are also subsidized by the government, government funds, which allows the leaders of the countries to demonstrate their direct and indirect involvement in sports, affecting the opening ceremonies, the official celebration of victory, manifested in the presence of 
the first persons of the state at conferences, seminars, matches, etc.

An important factor, as a result of which it became possible to form the phenomenon of sports diplomacy, is a deeper understanding of the essence, the role of sports, the growing role of sports, independent sports institutions and their activities aimed at strengthening the image of sports. Understanding of the whole value and overall attractiveness of sport for communications between the state and state structures with the international community, its citizens, which is also due to the growing popularity of various humanistic values of sport, the development of social trends and functions applicable to sport, including diplomacy [24, p. 37].

Researchers studying sports and sports diplomacy note the enormous potential of sports as a full-fledged diplomatic means, primarily attributing this to a fairly large sports audience, which is complemented by a general interest in sports around the world [11].

Thus, V. Mant, professor at the City University in New York, in the spirit of the liberal paradigm, motivates the use of sport as an "important sports component, the desire to promote democratic values, international cooperation, world peace" [10, p. 23]. J. Pigman from the University of Pretoria in South Africa, on the other hand, connects the growing importance of sport among various diplomatic tools, primarily based on existing ideas and the content of the "new public diplomacy", "involving the strengthening of the role of non-state actors and structures interacting along the axis "society - society", including the priority of the dialogue principle in international relations, touching upon the issue of the consistent formation of the network structure of communications" [16, p. 97].

Analyzing this thesis, B. Hawking, director of the Center for the Study of Foreign Policy and Diplomacy, noted that the new public diplomacy largely involves the rather active participation of various non-governmental organizations and other non-state actors, and is also characterized by the use of new instruments that are more in line with current, modern conditions in international relations, in comparison with the instruments of traditional public diplomacy. This is especially evident when considering the possibilities of sports, the massive nature of sports, and the popularity of sports in general [6, p. 41].

So, it is obvious that international sport today is actively used for ideological and political purposes, with an outlook for becoming the arena of dominant politics. As a result of state intervention in the field of sports, it becomes one of the strategic instruments of countries concerning foreign and domestic policy. Sport acts as a state machine of nonadministrative influence on public perception and collective representation.

\subsection{Figure Skating in Russia: Fulfillment of Soft Power and Diplomatic Potential}

In the context of sport, as one of the most effective platforms for the use of "soft power" and diplomacy, along with the participation and holding of a large-scale sports mega event by the state, the development and popularization of its individual types by the state is also an important factor.

Russia is entering a new period of development and positioning itself on the international stage, therefore, sports are becoming an integral part of the foreign policy of "soft power", and in this context, sport is especially relevant as an instrument of the state strategy of our country.

Traditionally preserving the Soviet legacy, figure skating in Russia, like hockey, has become more than just popular sports - in a sense, they can be called the personification of the nation, part of Russian culture and national heritage. The popularity of figure skating in Russia was promoted by sporting successes (for example, 5 medals in Sochi-2014), ice TV shows, and historical experience. According to sports agent M. Shashina, during the Soviet era, a lot of figure skating was broadcast on central TV, and the public was accustomed to regularly receive information about this sport. People who grew up watching figure skating on TV now fill the stands and bring their children and grandchildren to competitions and in sports clubs [7].

A study by the Moscow platform SportSensus confirms the above; in 2019 figure skating entered the top 5 most interesting sports for Russians, after hockey and football [3]. In this context, it is not surprising that every year in Russia there are more and more ice shows, and not only former but also current figure skaters are involved in them.

Such stars of figure skating as L. Pakhomova and A. Gorshkov, I. Rodnina and A. Zaitsev, who emigrated from the USSR, but became idols of figure skating fans all over the world for many years, L. Belousova and O. Protopopov remained for many years the same symbols of the nation as the legendary ice hockey team "Red Machine". And if now the Russian national ice hockey team is openly positioned and "presented" to the world community as a "Red Machine", the successor of the great victories of Soviet hockey players, officially reviving this brand, and using it in full in the national team's symbols, then, unfortunately, in figure skating, where after the collapse of the USSR, Russia won much more victories than in hockey, there is practically no similar activity in the positioning of this sport "with Russian specifics" at the international level.

A striking example of insufficient attention to the development of Russian figure skating on the international stage is the 2019 Russian Figure Skating Championship in Saransk, which revealed all the advantages and problems of one of the most popular sports in the country. In terms of the figure skaters skill level, Russia is a superpower, but in terms of the level of organization and promotion of figure skating to the international stage, our country loses significantly. It should be noted that the organization of the national figure skating championship was not at the due level.

In particular, even on the poster in the foyer of the sports palace, there was an image not of Russian stars but of the Italian figure skating star K. Kostner, who did not take part in the Russian championship. Also, neither the sale of souvenirs nor the holding of autograph sessions with the stars of 
Russian figure skating was organized [12]. Meanwhile, figure skating is one of the few sports where Russia performs as well as in Soviet times. And in women figure skating, Russia shows much more serious success than foreign stars of this sport: A. Sotnikova, Y. Lipnitskaya, E. Medvedeva, and A. Zagitova made a mash on millions of Russians and foreign figure skating fans becoming part of a national brand of figure skating. Besides, the best skaters of Russia with their performances each time change the idea of Russia as a country of total "state doping" in sports.

It should be noted that participation in any significant sporting mega-events and international competitions in itself is already a peculiar form of the state to declare itself. In general, the country's sports image is a phenomenon that exists within the framework of a historical retrospective, and Russia inherited the experience and glory of Soviet figure skating, at the same time having much more advantageous positions and relying on sports in the formation of its positive international image (for example, at the World Figure Skating Championships in Japan, Russia received five out of twelve awards, which was another very high indicator of the international level) [8, p. 300].

Also, since the sport is one of the most important means for international cultural exchange, it is necessary to note a clear example of the fusion of culture and sport at the Eurovision in 2008, when the Russian trio consisting of the popular performer D. Bilan, violinist E. Marton and the Olympic champion in figure skating E. Plushenko made a real show on the stage. E. Plushenko skated on a specially prepared ice rink to live violin music, which brought Russia to first place [1]. Also important is the fact that the grandiose performance of Russian pop and sports stars defused the situation that has matured in connection with the RussianGeorgian conflict, temporarily focusing the attention of the international community on cultural and sports achievements.

Also, a significant aspect of the implementation of soft power and an element of the use of Russian sports diplomacy in the context of figure skating may be the transfer of the figure skating championship to Russia in 2011 due to the earthquake and tsunami in Japan. After the end of the championship, Russian figure skating stars performed with a demonstration charity program, which raised funds and donations to help Japan overcome the consequences of the natural disaster [21].

Another example of the effective use of "soft power" by Russia through figure skating is the example of RussianJapanese interaction. In particular, figure skating is extremely popular both in Russia and in Japan, while Russia is also the recognized world leader in this sport. Based on this direction, the two countries have a high level of interaction. Thus, to maintain the image, at one of the sporting events for figure skating Dreams on Ice 2016 in Japan, the Russian world champion E. Medvedeva acted as the character of the popular anime "Sailor Moon", which caused an enthusiastic reception from the Japanese society [18]. In Japan, comics, cartoons, and posters with the face of a Russian figure skater began to be created throughout the country. The popularity of
Medvedeva in Japan does not subside, the Russian figure skater is often invited to various cultural and official events by Japanese diplomats, which intend to show Medvedeva as a symbol of good relations between the two countries. In many respects, therefore, it was Medvedeva who was chosen as Russia's ambassador to the Olympic Games in Tokyo in 2021. Various social polls show that, to a greater extent, it is Russian figure skaters that encourage the Japanese to be interested in Russian culture and the country as a whole. Also, this attitude towards Japanese culture was favorably received by the Japanese government, which in turn made it possible for the governments of the two countries to begin productive and conflict-free negotiations on the Kuril Islands and develop a dialogue on the signing of a peace treaty. Therefore, it should come as no surprise that Medvedeva was invited to give a speech at the J-FEST online Japanese culture festival.

Outstanding figure skating athletes play a significant role in improving attitudes towards Russia in the world. They change the image of Russia, which is taking shape in the world under the influence of Western masterminds, as a kind of not very predictable and not too peaceful state. A typical example of such positioning is the performance of E. Tuktamysheva the 2019 Championship, which temporarily interrupted the world's media outlets about Russia in the context of sanctions or accusations of "interference" in the internal affairs of other states.

Also, a vivid example of the influence of Russian sports stars' performance on the political background of relations between states can be a gift from the Japanese government $\mathrm{S}$. Abe to the Russian world champion in figure skating A. Zagitova. For the victory at the Olympics in South Korea, Japan presented the athlete with a dog, emphasizing that it "sincerely hopes that this dog can become a symbol of friendship between our countries" [25].

An advertisement for a Japanese mobile game, where both Russian figure skaters were presented in the image of sorceresses, characters from the anime "Puella Magi Madoka Magica Side Story", gained wide popularity. The video received about 3 million views, besides, posters with images of Medvedeva and Zagitova in outfits of the main characters appeared on one of the central transport hubs of the Tokyo metro.

In 2020, Evgenia Medvedeva took part in the preparation of the Christmas event for the Honkailmpact 3rd mobile game from the Chinese video game studio miHoYo, where Medvedeva played the S-rank Valkyrie Durandal.

Another example is Russian figure skater Alexandra Trusova, the only Russian woman, three times included in the Guinness Book of Records as the first performer of the quad toe loop, quad lutz, and quad flip at official competitions.

The state should more actively support Russian figure skating, not only for purely sporting reasons but even partly for political reasons. The share of total spending on physical education and sports in the federal budget in 2019 was only $0.5 \%$ [3], and the share of figure skating in these already insignificant expenses is negligible. It is also advisable for the state to start providing scholarships for talented young 
athletes to directly stimulate athletes and the development of figure skating in the country as a whole.

Despite the postponement of the World Cup and the early end of the season due to the Covid-19 pandemic, figure skating remains one of the most prestigious, recognizable, and popular sports. Russian athletes have won almost all medals at major competitions (four gold medals at the European Championship at once), Russian stars continue to hit the covers of glossy magazines, and coaches and the Russian Figure Skating Federation receive significant allowances for advertising contracts (in particular, an unprecedented amount of broadcasts figure skating received on Channel One). In the current crisis, this sport may even improve its position, since skaters do not require the same funding as football or hockey players, while they receive as much and sometimes more attention, presenting Russia at the international level as a great sports actor which fears not to declare himself.

Summing up, it is important to emphasize once again that figure skating is an integral part of the branding of the Russian nation, aimed at promoting its idea of openness to the world and, judging by the scale of its development, its status as a great power. Russia needs to make figure skating stars heroes of the nation and full-fledged world-class stars, as well as create conditions for the emergence of future stars since the chances of losing great achievements in sports always exist, and reviving a sport from scratch is much more difficult than developing, stimulating and maintaining the proper level, along the way bringing this sport to the degree of the international heritage.

\section{Conclusions}

As a result, based on the material presented, it is appropriate to note that the existing potential of Russian figure skating as a full-fledged "soft-power" resource of the Russian Federation is not at the level necessary for full and effective use.

One of the reasons for this situation is the relatively low level of attention from the state, sports structures, advertisers, investors, the Russian and foreign public to this sport (Russian figure skating), which leads to a relatively smaller amount of funding for this sport in comparison with more common and popular sports disciplines in the Russian Federation - mainly with football and hockey, which reflect a more complete presentation of both the state and private structures, sponsors, advertisers, and the public.

Another reason for the low potential of figure skating as a soft power resource of the Russian state is the relatively lower recognition of the representatives of this sport in the public, social, political, and international plane, which does not allow for the qualitative attraction of a large number of athletes from this sport to the cultural, public, political, humanitarian, and social programs. This encloses the skater into the so-called "dedicated niche", which presumes their role as participants in certain television shows, separate, but not massive in their target coverage of performances, social and charitable programs (however, the use of a football player as the "face of the project", due to his greater recognition, facilitates the promotion of certain charity project versus using a skater).

In turn, the low level of awareness and recognition of representatives of this sport, on the one hand, reduces the interest of advertisers and private sponsors, and, on the other hand, does not allow full use of this sport as an effective instrument of the soft power of the Russian state. The solution to this problem may be associated with an increase in the weight of athletes from this field, their involvement in state social and charitable projects with an increase in funding for this sports discipline.

Ultimately, within the framework of this study, it is also necessary to note the historical aspect. So, during the existence of the Soviet Union, the country's national leadership was directly interested in the high sports results of Soviet athletes on the international stage, which was associated with the perception of sports victories as the socalled "marker" of the total strength of the Soviet nation, whose successes extend not only to the military, political or geostrategic sphere, but also affect the processes of direct rivalry between sports representatives of the USSR and other countries (both friendly and rival). This circumstance, in turn, led to two characteristic tendencies.

1. Large-scale financial support from the state concerning a wide range of sports disciplines (creation of competitive sports schools, boarding schools, sports clubs, promotion of a healthy lifestyle, programs for involving young people in sports, which were positioned as an integral part of the life of every Soviet citizen).

2. High competition between sports schools and athletes directly, which created a wide choice of candidates for the coaching staff of the national team in almost any sport (for example, to a sports club or national team) who are interested both in achieving high sports results and in promoting (protecting) the interests of the Soviet state in the international arena, and in receiving prize payments.

The result of this approach was the formation, taking into account state support, of competitive teams in key (Olympic) sports, as a result of which sports achievements could be safely positioned by the Soviet leadership as a marker of the effectiveness of both the sports policy being implemented and the course of the Soviet state as a whole. However, due to the relatively weak development of information technologies, the full-fledged (based on today's views) positioning of sports achievements as an element of the soft power of the state could not affect broad target audiences, whose knowledge about the success of Soviet athletes was associated with sports public, or broadcasts of the Western media, limited in terms of volume or timing and focusing on the success of Western athletes.

On the other hand, after the collapse of the USSR, there was a consistent reduction in state funding for the vast majority of sports disciplines, which led to a decrease in the number of special sports sections, schools, centers for the preparation of international players in certain sports 
(including figure skating). This was accompanied by a decrease in financial interest on the part of private investors and advertisers, who were interested in the early years of the post-Soviet period not in financing individual sports, but in preserving their own sources of income, which put in a vulnerable position those sports disciplines which were traditionally strong during the Soviet period (except football and, with reservations, hockey). Another aspect, in this case, was the emergence of new information and digital technologies, the integration of these technologies into the life of society, which harmonized the possibilities of using sports achievements as a resource of "soft power" promoting the state on the international stage.

Thus, it should be noted that the relatively low potential of figure skating as an instrument of the state "soft power" is associated with the financial and sports "failure" that occurred after the collapse of the Soviet Union and marked a reduction in government funding for figure skating (including a decrease in attention from advertisers and investors associated with the transition period in the economic formation of the Russian Federation). As a result, the low representation of this sports discipline contributed to a decrease in spectator and public interest in this sport, making impossible the full (at the level of, for example, football or hockey), use of this discipline as a resource of soft power in the Russian Federation. On the other hand, assessing the positive aspects, it should be noted that in recent years the informatization of the international community has increased, which makes it possible to situationally draw attention to sports achievements in this plane both with the help of traditional (journalism, television, newspapers) and new media (social networks, blogs, Internet resources). This leaves opportunities, subject to an increase in public and private interest in this sport, to strengthen the potential of figure skating, which in the future will make it possible to use this sport as a fullfledged source of soft power for the Russian Federation by recreating the school of figure skating, training programs for athletes, funding athletes and the achievement of high results by Russian athletes at international forums, as well as coverage of these results, both in domestic and foreign media.

\section{References}

[1] Alekseev A., Alperina S. (2008). It's hard to believe // Russian Gazette. May 25, 2008. [Electronic resource] URL: https://rg.ru/2008/05/26/bilan.html (date of access: 09/21/2020).

[2] Anholt S. (2010). Places: Identity, image and reputation. London: Palgrave Macmillan.

[3] Application to the federal law on the federal budget for 2019 and the planning period of 2020 and 2021's // [Electronic resource] URL: https://www.minfin.ru/common/upload/library/2018/12/main/ BDG_2019_all.pdf (date of accessed: 09/22/2020).
[4] Bogolyubova N. M., Nikolaeva Yu. V. (2018). Geopolitics of sports and the foundations of sports diplomacy. Moscow: Yurayt.

[5] Evdokimov E. (2010) Olympic diplomacy of China // International processes. 2010. T. 8. No. 2. [Electronic resource] URL: http://www.intertrends.ru/seventeenth/007.htm. (date of access: 19.09.2020).

[6] Hocking B. (2005). Rethinking the «New» Public Diplomacy // The New Public Diplomacy. Soft Power in International Relations. New York: Palgrave Macmillan.

[7] Kalinina N. (2020) "An elf outwardly, an unbending warrior inside" // Forbes. July 6, 2020. [Electronic resource] URL: https://www.forbes.ru/biznes/404275-vneshne-elf-vnutrinesgibaemyy-voin-kak-18-letnyaya-alina-zagitova-zarabotalaza-god (date accessed: 20.09.2020).

[8] Kruglova Y. U. (2017). V. Sport as a symbol of high achievements // Modern problems of management and regulation: theory, methodology, practice. Collection of articles of the II international scientific and practical conference. / Under total. ed. G. Yu. Gulyaev. Penza: Science and Education.

[9] Kylasov A. (2010). The people are waiting for the exodus of sports officials. // Slon.ru. March 3, 2010. [Electronic resource] URL: http://www.slon.ru/blogs/kylasov/post/308267 (date of access: 09/18/2020).

[10] Munt V. (2015). Game, Set, Match: Sports and the Future of Diplomacy. New York: CUNY Academic Works.

[11] Murray S. (2011). Sports-Diplomacy: a hybrid of two halves // [Electronic resource] URL: http://www.culturaldiplomacy.org/academy/content/pdf/partic ipantpapers/2011-symposium/Sports-Diplomacy-a-hybrid-oftwo-halves--DrStuart-Murray.pdf (date of accessed: 09/19/2020).

[12] Not for sale: why our skaters don't roll // [Electronic resource] URL:

https://www.gazeta.ru/comments/2018/12/24e12106201.shtml (date of accessed: 09/21/2020).

[13] Nye J. (2005). Soft Power. The Means to Success in World Politics. New York: Public Affairs.

[14] Nye J. (2008). Public diplomacy and soft power. // Annals of the American Academy of Political and Social Science, 2008, № 616: 94-109.

[15] Nye J. (2004). Soft Power: The Means to Success in World Politics // [Electronic resource] URL: https://www.belfercenter.org/sites/default/files/legacy/files/j oe_nye_wielding_soft_power.pdf (date of accessed: 09/15/2020).

[16] Pigman G. A. (2014). International Sport and Diplomacy's Public Dimension: Governments, Sporting Federations and the Global Audience // Diplomacy \& Statecraft, 2014, № 25: 94114.

[17] Putin called the results of Russian women in figure skating stunning // [Electronic resource] URL: https://news.sportbox.ru/Vidy_sporta/Figurnoe_katanie/spbne ws_NI1143262_Putin_nazval_rezultaty_rossijanos_v_figurni mom_katanii date: 14 _figurnhimom_katanii (date of access: $09 / 18 / 2020)$. 
[18] Russian figure skater in the image of Sailor Moon conquered the Japanese // [Electronic resource] URL: https://www.topnews.ru/news_id 91246.html (date of accessed: 09/22/2020).

[19] Signitzer B. H., Coombs T. (1992). Public relations and public diplomacy: Conceptual convergences. // Public Relations Review, 1992, № 18: 137-147.

[20] "Sport has the power to change the world" - Nelson Mandela // Paradigm Sports. September 23, 2017. [Electronic resource] URL: https://www.paradigmsports.ca/sport-power-changeworld-nelson-

mandela/\#: :text=It\%20has\%20the\%20power\%20to,in\%20br eaking\%20down\%20racial\%20barriers (date of accessed: $09 / 16 / 2020)$.

[21] Svyatenkov: "Sports diplomacy increases the prestige of the Russian Federation" // [Electronic resource] URL: $\mathrm{http}: / /$ actualcomment.ru/svyatenkov sportivnaya diplomatiya _povyshaet_prestizh_rf.html (date of accessed: 09/22/2020).
[22] Szondi G. (2010). From image management to relationship building: A public relations approach to nation branding. // Place Branding and Public Diplomacy, 2010, № 6: 333-343.

[23] Vyazantsev V. (2018). The ball was blown away. Sociological studies of recent years show that football is not the most popular sport // Altai sport. 12 October, 2018. [Electronic resource] URL: http://www.altaisport.ru/post/16093 (date of accessed: 09/21/2020).

[24] Wolfram M. (2010) Global Movements, sports Spectacles and the Transformation of Representational Power // Asia Pacific World, 2010, № 1: 37-55.

[25] Zagitova was presented with an Akita Inu puppy for winning the Olympics // Sport RIA news. May 26, 2018. [Electronic resource] URL: https://rsport.ria.ru/20180526/1137348383.html (date of access: 09/22/2020). 